\title{
An Environment-Friendly Process Featuring Calcified Roasting and Precipitation Purification to Prepare Vanadium Pentoxide from the Converter Vanadium Slag
}

\author{
Juhua Zhang ${ }^{1,2,3, *}$, Wei Zhang ${ }^{1,2,3}$ and Zhengliang Xue ${ }^{1,2,3}$ \\ 1 The State Key Laboratory of Refractories and Metallurgy, Wuhan University of Science and Technology, \\ Wuhan 430081, China; wei_zhang@wust.edu.cn (W.Z.); xuezhengliang@wust.edu.cn (Z.X.) \\ 2 Key Laboratory for Ferrous Metallurgy and Resource Utilization of Ministry of Education, Wuhan \\ University of Science and Technology, Wuhan 430081, China \\ 3 Hubei Provincial Key Laboratory for New Processes of Ironmaking and Steelmaking, Wuhan University of \\ Science and Technology, Wuhan 430081, China \\ * Correspondence: Judyzjh@hotmail.com
}

Received: 21 November 2018; Accepted: 21 December 2018; Published: 25 December 2018

check for updates

\begin{abstract}
Converter vanadium slag is a byproduct of the iron making process when the vanadium titanomagnetite is used as iron raw material. A cleaner process including calcified roasting, dilute acid leaching, precipitation purification, vanadium precipitation with ammonium salt, followed by thermal decomposition was proposed to extract vanadium resource from this slag. And then vanadium pentoxide with purity over $98 \%$ was prepared, which can be used as additives for high strength low alloy steel production. A total vanadium recovery beyond $80 \%$ was achieved in this whole process. Since no sodium and potassium salt was introduced, wastewater generated was closed-circulating after removing the enriched impurities of $\mathrm{P}, \mathrm{Si}, \mathrm{Ti}$ and $\mathrm{Cr}$ with adding powder $\mathrm{CaO}$. The content of $\mathrm{V}_{2} \mathrm{O}_{5}$ in residues after vanadium extraction was lower than $1.2 \mathrm{wt} . \%$, while other valuable metals like $\mathrm{Fe}, \mathrm{Mn}, \mathrm{Cr}$ and Ti were concentrated. With no alkaline metal salts added in this process, the metal resources of $\mathrm{Fe}, \mathrm{Mn}, \mathrm{Cr}$ and $\mathrm{Ti}$ in the residues were more feasible to be recovered with pyrometallurgy processes.
\end{abstract}

Keywords: converter vanadium slag; calcified roasting; dilute acid leaching; chemical precipitation purification; cleaner process

\section{Introduction}

As a very important material, vanadium is widely applied in the iron and steel industry, aviation and aerospace, chemical and pharmaceutical industry. About $85 \%$ of the total vanadium in the world was consumed for production of high-strength low alloy steel [1], and others were mainly used to produce alloy, catalyst and metallopharmaceuticals and so on [2,3]. Presently, the primary vanadium resources are converter vanadium slag, stone coal, steel slag and spent catalyst. The converter vanadium slag that is a by-product of vanadium titanomagnetite smelting process accounted for more than $50 \%$ of the world overall vanadium production and the content of $\mathrm{V}_{2} \mathrm{O}_{5}$ in this slag is usually $8-21 \mathrm{wt} . \%$.

The conventional process of sodium salt roasting followed by water leaching for vanadium extraction from the vanadium slag is mature and operationally steady. However, it seriously pollutes the environment, and has difficulties in comprehensive utilization of the leaching residue and in the recycling of wastewater, which contains high concentration of sodium. Consequently, some novel 
processes for cleaner vanadium extraction have been proposed, like roasting without adding salt [4], submolten salt extraction [5-7], alkali decomposition enhanced by electrochemistry [8], direct acid leaching [9-11], sulfating roasting [12] and calcified roasting followed by dilute acid leaching [13,14]. Vanadium extraction with calcium salt roasting is increasingly concerned these years due to its lower cost of roasting additive, no emission of pollutional gas, like $\mathrm{HCl}, \mathrm{Cl}_{2}, \mathrm{SO}_{2}$ and $\mathrm{SO}_{3}$, and no sodium contained in subsequent leaching residual and wastewater. Besides, the roasted vanadium slag with calcium is usually leached by dilute sulfuric acid with relatively higher selectivity for vanadium, and then a weakly acidic vanadium solution is obtained, which is beneficial to subsequent purification procedure [15]. The calcified roasting-dilute acid leaching process was first proposed and carried out by the Tula Vanadium Factory in 1974 [16]. Hereafter, Pangang Research Institute also made a lot of research on this process [17-21]. However, because the problem of purifying the acidic vanadium solution was still unsolved, the purity of vanadium pentoxide was only $93-94 \%$ and was inferior to the vanadium pentoxide prepared by the sodium roasting process. In this paper, a cleaner process including calcified roasting, dilute acid leaching, precipitation purification, vanadium precipitation with ammonium salt followed by thermal decomposition was proposed to extract vanadium resource from the converter vanadium slag, and this process was evaluated in respective of vanadium recovery, quality of the vanadium pentoxide product and its influence imposed on environment.

\section{Materials}

The chemicals used in this study $\left(\mathrm{CaO}, \mathrm{H}_{2} \mathrm{SO}_{4}, \mathrm{NH}_{4} \mathrm{~F}, \mathrm{MnSO}_{4},\left(\mathrm{NH}_{4}\right)_{2} \mathrm{~S}_{2} \mathrm{O}_{8}\left(\mathrm{NH}_{4}\right)_{2} \mathrm{SO}_{4}\right.$, $\mathrm{H}_{2} \mathrm{C}_{2} \mathrm{O}_{4} \cdot 2 \mathrm{H}_{2} \mathrm{O}$ and ammonia water) were all of analytical grade (Sinopharm Chemical Reagent $\mathrm{Co}$., $\mathrm{Ltd}$, Shanghai, China). Powder $\mathrm{CaO}$ was used as the additive for roasting vanadium slag and was dried in an oven at $120^{\circ} \mathrm{C}$ for $24 \mathrm{~h}$ before use. Water used in experiments was deionized one time.

Vanadium slag was supplied by Sichuan Weiyuan Iron \& Steel Co., Ltd., Chengdu, China (after magnetic separation). After screening, the slag with particle size within 48-75 $\mu \mathrm{m}$ was chosen for roasting experiments. Based on chemical composition analysis, it was found that this slag contained $14.3 \%$ $\mathrm{V}_{2} \mathrm{O}_{5}, 14.3 \% \mathrm{SiO}_{2}, 24.8 \% \mathrm{FeO}$, 2.3\% metal iron, 9.9\% $\mathrm{CaO}, 8.5 \% \mathrm{MnO}, 7.4 \% \mathrm{TiO}_{2}, 4.4 \% \mathrm{Cr}_{2} \mathrm{O}_{3}, 3.7 \% \mathrm{MgO}$, $2.1 \% \mathrm{Al}_{2} \mathrm{O}_{3}$ and $0.22 \% \mathrm{P}$. The mass ratio of $\mathrm{CaO}$ to $\mathrm{V}_{2} \mathrm{O}_{5}$ is much larger than 0.22 , indicating it belongs to grade 3 of FZ3 vanadium slag in China, and the vanadium recovery would be lower if it was treated by the conventional sodium roasting process due to the generation of undissolved calcium vanadate. Mineral phase composition of the slag was analyzed by X-ray diffraction (X'Pert Pro MPD, PAnalytical B.V., Almelo, Netherlands) and it was found that the slag was mainly composed of vanadium spinel (Mn, $\mathrm{Fe})(\mathrm{V}, \mathrm{Cr})_{2} \mathrm{O}_{4}$, fayalite $\mathrm{Fe}_{2} \mathrm{SiO}_{4}$, augite $\mathrm{Ca}(\mathrm{Fe}, \mathrm{Mg}) \mathrm{Si}_{2} \mathrm{O}_{6}$ and a small amount of magnesium titanium oxide $\mathrm{Mg}_{2} \mathrm{TiO}_{4}$. The SEM graph of this slag sample and the corresponding EDS microanalysis data for different areas (SSX-550, Shimadzu Corporation, Kyoto, Japan) were shown in Figure 1.

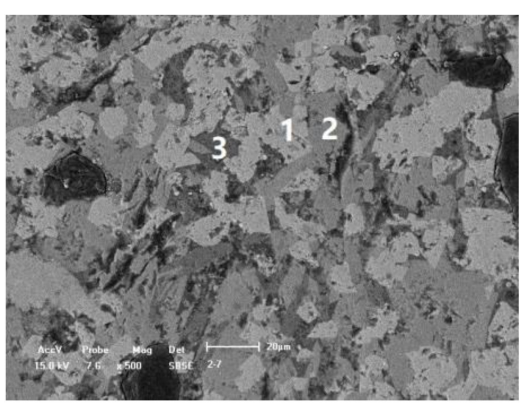

(a)

\begin{tabular}{ccccccccccc}
\hline & \multicolumn{10}{c}{ Elements (weight, \%) } \\
\cline { 2 - 11 } & $\mathrm{O}$ & $\mathrm{V}$ & $\mathrm{Cr}$ & $\mathrm{Fe}$ & $\mathrm{Mn}$ & $\mathrm{Ti}$ & $\mathrm{Mg}$ & $\mathrm{Si}$ & $\mathrm{Ca}$ & $\mathrm{Al}$ \\
\hline 1 & 20.99 & 24.40 & 8.31 & 22.14 & 15.37 & 5.60 & 1.58 & 0.41 & & 1.22 \\
2 & 24.17 & & & 18.96 & 23.96 & & 2.08 & 17.48 & 13.33 & \\
3 & 37.01 & & & 8.86 & 7.24 & & & 27.01 & 8.29 & 11.60 \\
\hline
\end{tabular}

(b)

Figure 1. Scanning electron microscope and energy dispersive spectrometer (SEM-EDS) analysis for the converter vanadium slag (a) the scanning electron micrograph of the converter vanadium slag; (b) the energy dispersive spectrum analysis for different areas in Figure 1a. 
Combining the chemical composition, phase composition with the scanning electron microscope and energy dispersive spectrometer (SEM-EDS) analysis of the raw vanadium slag, we knew that the main vanadium-bearing phase (white area in Figure 1) was vanadium spinel [(Mn, Fe) $\left.(\mathrm{V}, \mathrm{Cr})_{2} \mathrm{O}_{4}\right]$ which was wrapped by the matrix phases-fayalite (gray area) and augite (black area); the content of $\mathrm{Si}$ in augite was higher than that in fayalite; $\mathrm{Fe}$ was distributed as $\mathrm{Fe}^{2+}$ in spinel, fayalite and augite phases.

\section{Experimental}

The whole flow chart for treating the converter vanadium slag was displayed as Figure 2. Roasting experiments were carried out in a vertical tube furnace controlled by a Shinaden SR-53 temperature programmed instrument with molybdenum disilicide heating elements. Leaching, purification and vanadium precipitation were conducted in three-necked glass vessels centered in a thermostatic water bath (HH-4, China Changzhou Sino Instrument Co., LTD, Changzhou, China) and the pH values were measured by a $\mathrm{pH}$-meter (Starter 3C). The operational parameters have been optimized in our previous studies [22-24].



Figure 2. Flow chart for treating the converter vanadium slag.

The vanadium slag $(48-75 \mu \mathrm{m})$ was mixed with additive of $\mathrm{CaO}$ at a mass ratio $(\mathrm{CaO}) /\left(\mathrm{V}_{2} \mathrm{O}_{5}\right)$ of 0.42 and prepared into $\phi 8-10 \mathrm{~mm}$ pellets. The pellets were heated to $850{ }^{\circ} \mathrm{C}$ at rate of $2{ }^{\circ} \mathrm{C} / \mathrm{min}$ from room temperature and then held for $150 \mathrm{~min}$. When the holding time was completed, the roasted pellets were quenched to room temperature and ground to fine powder. Roasting efficiency was expressed by vanadium recovery upon leaching, and the leaching conditions were liquid to solid ratio of 3:1, temperature of $55^{\circ} \mathrm{C}$, time of $30 \mathrm{~min}$, $\mathrm{pH}$ of 2.5 and stirring speed of $500 \mathrm{rpm}$.

Because the lower selectivity of dilute acid leaching, some impurities of $\mathrm{Ca}, \mathrm{Mg}, \mathrm{Si}, \mathrm{Al}$, and $\mathrm{Mn}$ transferred into vanadium solution accompanying with $\mathrm{V}$, and which in turn affected vanadium 
precipitation rate and quality of final product. According to analyses for occurrence of impurities and vanadium in leaching solution, neutralization separation could be adopted to remove $\mathrm{Si}$ and $\mathrm{Al}$, during which the solution $\mathrm{pH}$ value was adjusted to $4.5 \pm 0.05$. Taking into consideration of decreasing the vanadium loss, $\mathrm{Ca}, \mathrm{Mg}, \mathrm{Al}$ and $\mathrm{Si}$ were removed simultaneously through adding a composite reagent of $\mathrm{MnNH}_{3} \mathrm{~F}_{3}$ to precipitate $\mathrm{Ca}, \mathrm{Mg}$ and adjusting the solution $\mathrm{pH}$ to remove $\mathrm{Al}$ and $\mathrm{Si}$. The purification conditions were set as stirring speed of $200 \mathrm{rpm}$, reagent adding amount of 1.6 (molar ratio of $2 n(\mathrm{~F}) / n(\mathrm{Ca}+\mathrm{Mg})$ ), temperature of $50{ }^{\circ} \mathrm{C}$ and time of $30 \mathrm{~min}$. Besides, flocculant polyacrylamide and diatomaceous earth (DA-1) were used to improve sedimentation and filtration respectively during the purification process.

Mn in solution was not removed before vanadium precipitation step and ammonium salt was added to precipitate vanadium since this method can alleviate the side effect of $\mathrm{Mn}$ on the quality of final product compared with hydrolysis precipitation. Vanadium precipitation step was conducted at $\mathrm{pH} 2.00 \pm 0.05$ and temperature of $95{ }^{\circ} \mathrm{C}$, ammonium sulfate was added at molar ratio $\left(\mathrm{NH}_{3}\right) /(\mathrm{V})$ of 1.5, and the reaction time was controlled in $120 \mathrm{~min}$. Some Vanadium precipitation was heated at $550{ }^{\circ} \mathrm{C}$ for $2 \mathrm{~h}$ and then saffron yellow powder of vanadium pentoxide was obtained. The vanadium precipitation and vanadium pentoxide were characterized by XRD (X'Pert Pro MPD, PAnalytical B.V., Almelo, Netherlands), SEM-EDS (SSX-550, Shimadzu Corporation, Kyoto, Japan) and laser particle size analyzer (Mastersizer 2000, Malvern Panalytical, Malvern, UK).

\section{Results}

\subsection{Roasting and Leaching}

The XRD and SEM graphs for the roasted slag were shown in Figures 3 and 4. After roasting the fayalite and vanadium spinel phases were destroyed. $\mathrm{V}^{3+}$ and $\mathrm{Fe}^{2+}$ contained in the converter vanadium slag were oxidized into $\mathrm{V}^{5+}$ and $\mathrm{Fe}^{3+}$. The mechanism of vanadium slag roasting with powder $\mathrm{CaO}$ has been reported in our previous studies [13,22]. Calcium vanadate and $\mathrm{Fe}_{2} \mathrm{O}_{3}$ were generated as illustrated by the light gray area (area 1) and white area (area 4 ) in Figure 3 respectively. Besides that, new silicate phases (area 2 and area 3 ) formed.

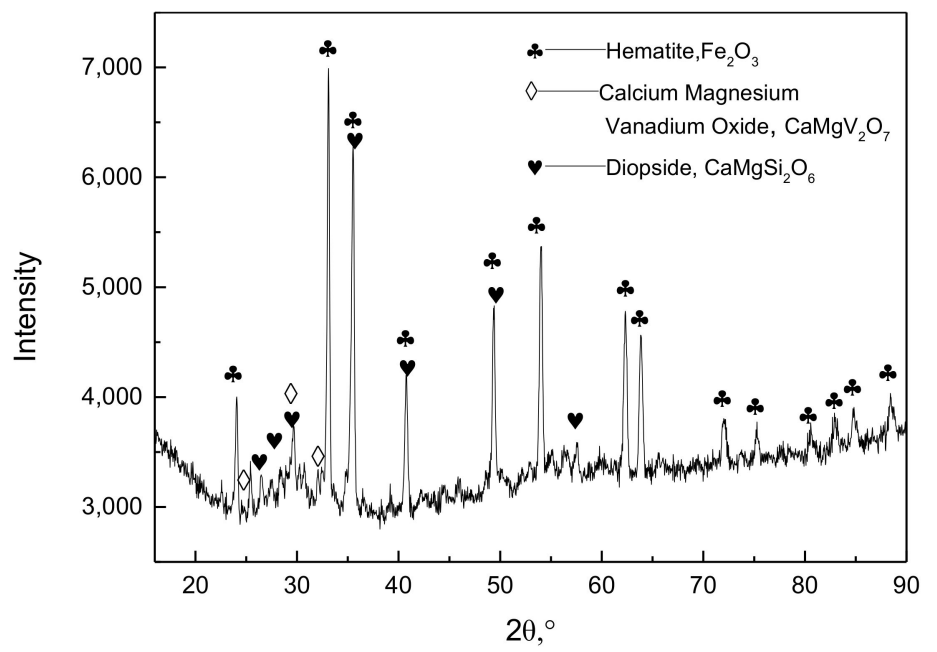

Figure 3. X-ray diffraction pattern for vanadium slag roasted at $850{ }^{\circ} \mathrm{C}$ for $150 \mathrm{~min}$.

The roasted slag was ground into a certain size range and screened for the subsequent leaching experiments. Compared with the conventional water leaching or alkaline leaching in the sodium roasting process, dilute acid leaching used in the calcified roasting process performs lower selectivity over the target element of vanadium. The effect of $\mathrm{pH}$ of leaching solution on leaching rate of $\mathrm{V}, \mathrm{Ca}$, $\mathrm{Al}, \mathrm{Mg}, \mathrm{Si}, \mathrm{P}, \mathrm{Fe}$ and $\mathrm{Mn}$ were shown in Figures 5 and 6. 




(a)

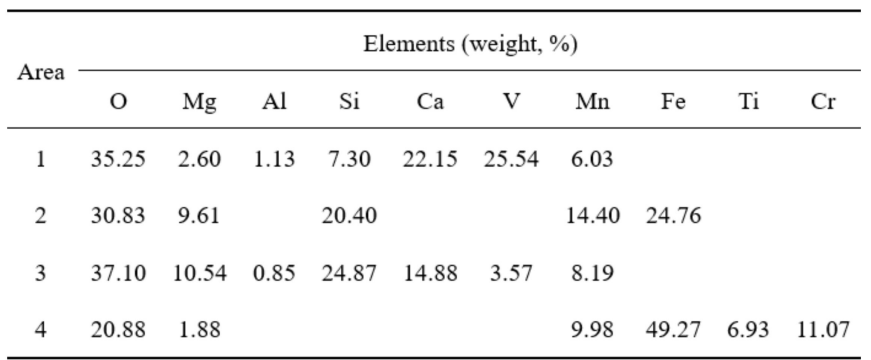

(b)

Figure 4. SEM-EDS analysis for the sample roasted at $850{ }^{\circ} \mathrm{C}$ for $150 \mathrm{~min}$ (a) the scanning electron micrograph of the roasted slag; (b) the energy dispersive spectrum analysis for different areas in Figure $4 \mathrm{a}$.

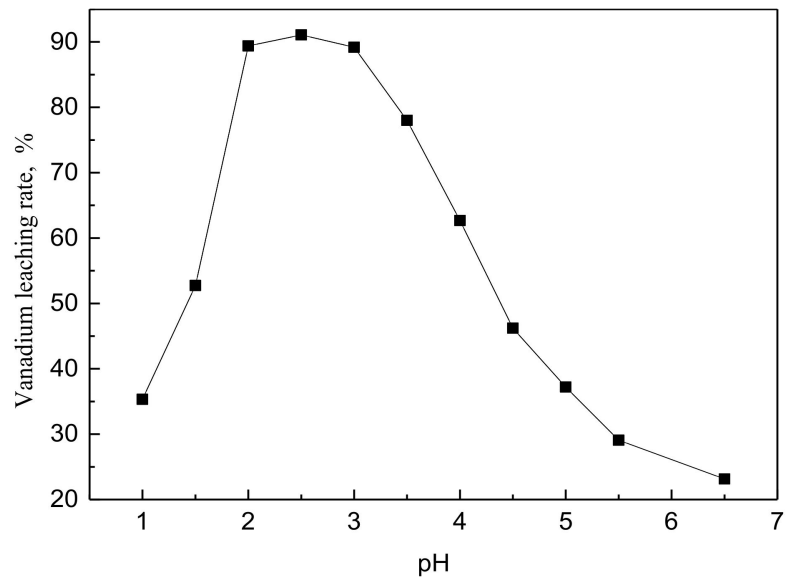

Figure 5. Effect of $\mathrm{pH}$ on the vanadium leaching rate (particle size of 75-96 $\mu \mathrm{m}$, time of $60 \mathrm{~min}$, $T=65^{\circ} \mathrm{C}, L / S=4$, stirring speed of $500 \mathrm{rpm}$ ).

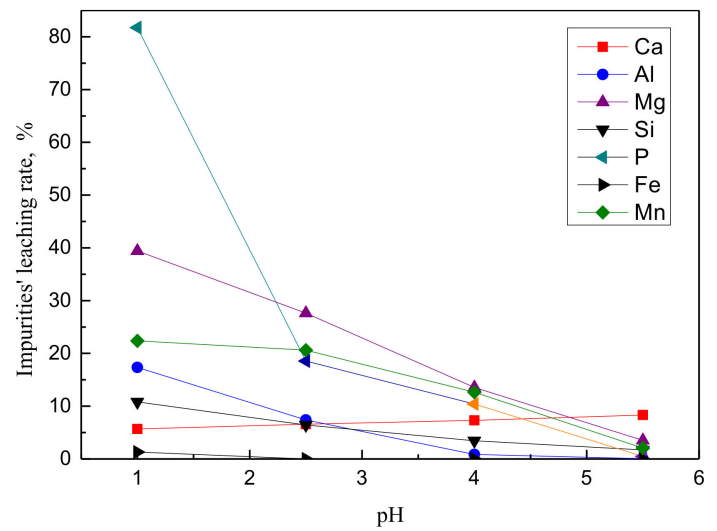

Figure 6. Effect of $\mathrm{pH}$ on the leaching rate of impurities (particle size of 75-96 $\mu \mathrm{m}$, time of $60 \mathrm{~min}$, $T=65^{\circ} \mathrm{C}, L / S=4$, stirring speed of $500 \mathrm{rpm}$ ).

It can be seen from the Figure 5 that the $\mathrm{pH}$ of leaching solution notably influences the recovery of vanadium. Increasing the acidity of the solution is beneficial to dissolution of calcium vanadate, but meanwhile, the concentration of $\mathrm{SO}_{4}{ }^{2-}$ is increased as well, leading to more generation of insoluble calcium sulfate that will wrap the unreacted particle of roasted slag. Additionally, when the $\mathrm{pH}$ is lower than 2.0, vanadium in the solution is converted into insoluble vanadium oxides $\mathrm{V}_{2} \mathrm{O}_{5}$ [23]. Within the $\mathrm{pH}$ range of 2 to 3, a satisfactory vanadium recovery of $90 \%$ is achieved. From the Figure 6 we know that except $\mathrm{Ca}$ other impurities of $\mathrm{Fe}, \mathrm{Mn}, \mathrm{Mg}, \mathrm{Al}, \mathrm{Si}, \mathrm{P}$ all transfer into the solution more as the $\mathrm{pH}$ decreases. The reason for the decrease of calcium leaching rate lies in the increase of $\mathrm{SO}_{4}{ }^{2-}$ 
as the acidity is improved. Since the leaching rate of Fe is lower over the whole $\mathrm{pH}$ range (pH 1-6) and its concentration is below $0.001 \mathrm{~g} \cdot \mathrm{L}^{-1}$, so the effect of Fe on the subsequent procedures is ignored. Combining the Figures 5 and 6, we found that when the most vanadium was extracted from the roasted slag, the impurities of $\mathrm{Fe}, \mathrm{Mn}, \mathrm{Mg}, \mathrm{Al}, \mathrm{Si}$ and $\mathrm{P}$ inevitably went into the solution.

Under the stated roasting and leaching conditions in the experimental section, the vanadium leaching rate was beyond $91 \%$, and meanwhile $10-30 \%$ impurities of $\mathrm{Ca}, \mathrm{Mn}, \mathrm{Mg}, \mathrm{Al}, \mathrm{Si}, \mathrm{P}$ were dissolved into the solution.

\subsection{Purification of Vanadium-Bearing Solution}

After roasting and leaching under optimized conditions, the obtained vanadium-bearing solution contained vanadium around $20 \mathrm{~g} / \mathrm{L}$ which meets the requirements for vanadium concentration in the subsequent vanadium precipitation step. However, since the impurities contained in the solution will bring side effects on vanadium precipitation rate and quality of vanadium pentoxide, they have to be removed. In this study, a composite fluoride was used to remove $\mathrm{Ca}, \mathrm{Mn}, \mathrm{Al}$ and $\mathrm{Si}$ at constant $\mathrm{pH}$ of $4.50 \pm 0.05$. This composite reagent was prepared through reaction between $\mathrm{MnSO}_{4} \cdot \mathrm{H}_{2} \mathrm{O}$ and $\mathrm{NH}_{4} \mathrm{~F}$ for $20 \mathrm{~min}$ at molar ratio of $1 / 7$ and temperature of $70{ }^{\circ} \mathrm{C}$ followed by filtration and washing several times to remove the free $\mathrm{NH}_{4}{ }^{+}$and $\mathrm{SO}_{4}{ }^{2-}$. The white precipitate was then dried at $80{ }^{\circ} \mathrm{C}$ for $120 \mathrm{~min}$ for chemical analysis and characterization with XRD. It was found the mass ratio of $F$ to Mn contained in this white powder was close to 1.0 and its XRD pattern was shown in Figure 7. It can be seen that the produced powder is mainly composed of $\mathrm{Mn}\left(\mathrm{NH}_{4}\right) \mathrm{F}_{3}$, which is called as a composite reagent, and this composite reagent is represented by $\mathrm{Mn}\left(\mathrm{NH}_{4}\right) \mathrm{F}_{3}$ to facilitate the calculation of adding amount.

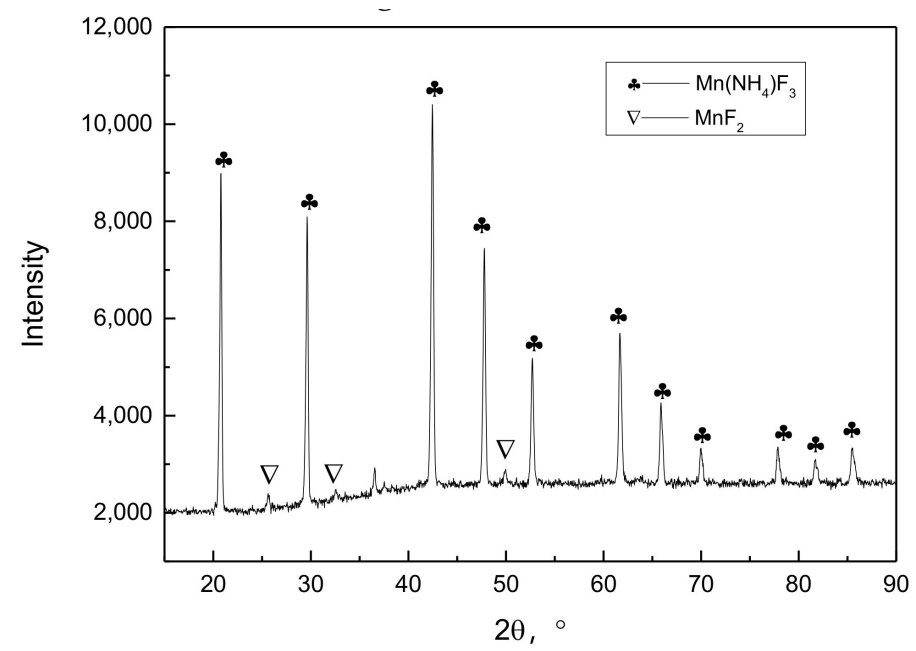

Figure 7. X-ray diffraction (XRD) pattern of the composite reagent for removing impurities.

Because $\mathrm{F}^{-}$is feasible to react with $\mathrm{Ca}^{2+}$ and $\mathrm{Mg}^{2+}$ under weakly acidic conditions, producing $\mathrm{CaF}_{2}$ and $\mathrm{MgF}_{2}$ with smaller solubility product constants, $\mathrm{Ca}^{2+}$ and $\mathrm{Mg}^{2+}$ can be separated from the vanadium-bearing solution with the composite reagent. At the same time, as the solution $\mathrm{pH}$ value go up after the composite reagent is added, impurities of $\mathrm{Al}^{3+}$ and $\mathrm{Si}^{4+}$ can be removed simultaneously due to hydrolysis. The composite reagent is slightly water-soluble, and the excess amount will be separated along with precipitation of $\mathrm{Ca}, \mathrm{Mg}, \mathrm{Al}$ and $\mathrm{Si}$ through filtration. With adding the composite fluoride of $\mathrm{Mn}\left(\mathrm{NH}_{4}\right) \mathrm{F}_{3}$ the removal efficiencies for $\mathrm{Ca}, \mathrm{Mg}$ and $\mathrm{Al}$ were all over 95\% and for Si was $55 \%$. In purification process some polyacrylamide and diatomite were also added to improve settleability and filtering quality of slurry. The loss of vanadium was lower than $5 \%$ during the whole purification. The concentrations of $\mathrm{V}$ and main impurities contained in vanadium-bearing solution before and after purification were given in Table 1. 
Table 1. Concentrations of $\mathrm{V}$ and main impurities contained in the of vanadium-bearing solution $\left(\mathrm{g} \cdot \mathrm{L}^{-1}\right)$.

\begin{tabular}{ccccccccccc}
\hline Elements & $\mathbf{V}$ & $\mathbf{M n}$ & $\mathbf{S i}$ & $\mathbf{A l}$ & $\mathbf{C a}$ & $\mathbf{F e}$ & $\mathbf{M g}$ & $\mathbf{C r}$ & $\mathbf{T i}$ & $\mathbf{P}$ \\
\hline Before Purification & 21.4 & 5.99 & 1.49 & 0.20 & 1.02 & 0.010 & 1.59 & 0.010 & 0.0057 & 0.12 \\
After Purification & 19.8 & 10.1 & 0.88 & 0.009 & 0.033 & 0.009 & 0.079 & 0.010 & 0.004 & 0.089 \\
\hline
\end{tabular}

\subsection{Vanadium Precipitation with Ammonium Salt and Thermal Decomposition}

After purification, the concentrations of $\mathrm{Ca}, \mathrm{Mg}$ and $\mathrm{Al}$ decreased to 33, 79 and $9 \mathrm{mg} \cdot \mathrm{L}^{-1}$ respectively, and only the concentration of $\mathrm{Mn}$ increased, which was caused by the reactions between $\mathrm{Mn}\left(\mathrm{NH}_{4}\right) \mathrm{F}_{3}$ and $\mathrm{Ca}^{2+}, \mathrm{Mg}^{2+}$ during the purification process. Vanadium was concentrated and precipitated with $\left(\mathrm{NH}_{4}\right)_{2} \mathrm{SO}_{4}$ from the purified solution at initial $\mathrm{pH}$ of 2.5 , and precipitation efficiency was over $96 \%$. Then the precipitation product was heated at $550{ }^{\circ} \mathrm{C}$ for $2 \mathrm{~h}$, and saffron yellow vanadium pentoxide powder was produced. The XRD and SEM-EDS for product of vanadium precipitation were given in Figures 8 and 9, and the particle size distributions for the precipitation product and the vanadium pentoxide were shown in Figure 10. The chemical composition of the vanadium pentoxide product was presented in Table 2.

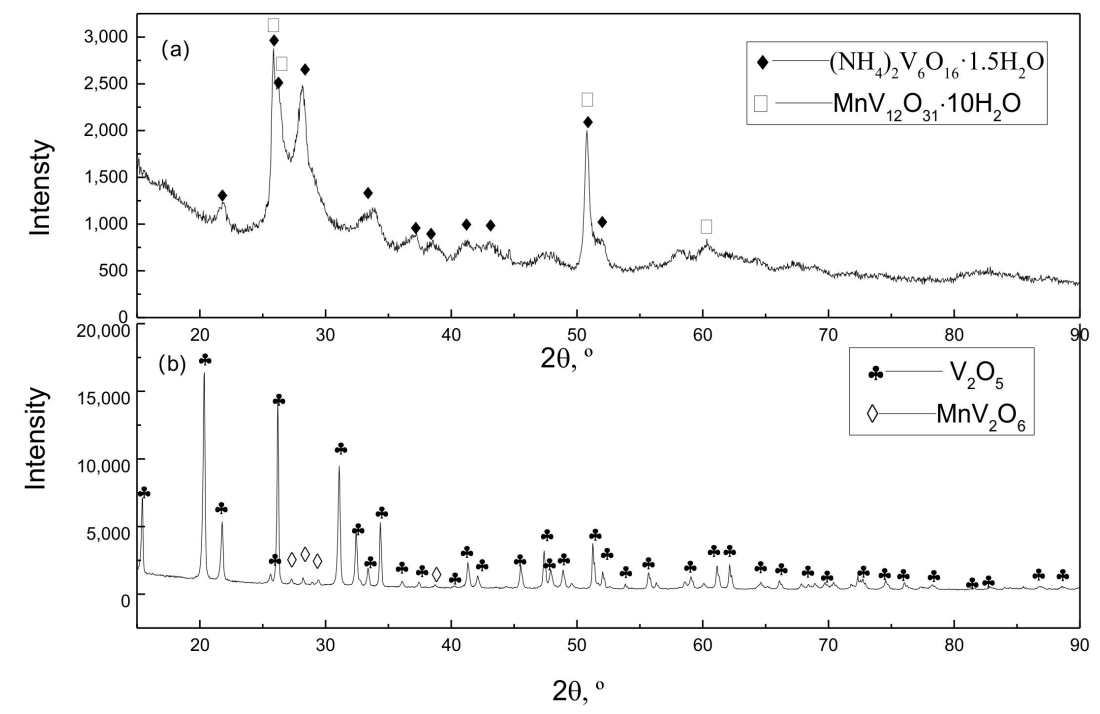

Figure 8. XRD pattern for products of vanadium precipitate (a) ammonium poly-vanadate;

(b) vanadium pentoxide.

The precipitated product was hydrated hexamer of ammonium vanadate $\left(\mathrm{NH}_{4}\right)_{2} \mathrm{~V}_{6} \mathrm{O}_{16} \cdot 1.5 \mathrm{H}_{2} \mathrm{O}$ existing in spherical and cylindrical structure with average particle diameter of $43.9 \mu \mathrm{m}$. The powder vanadium pentoxide was obtained after calcination of ammonium poly-vanadate $\left(\mathrm{NH}_{4}\right)_{2} \mathrm{~V}_{6} \mathrm{O}_{16} \cdot 1.5 \mathrm{H}_{2} \mathrm{O}$ and it was present in cylindrical shape with average grain size of $1.25 \mu \mathrm{m}$. The main impurity in the product was manganese in occurrence of metavanadate $\left(\mathrm{MnV}_{2} \mathrm{O}_{6}\right)$. According to chemical composition analysis, it was found that the obtained product met the national standard of 98 grade vanadium pentoxide (Chinese GB3283-87), which requires the impurities of $\mathrm{Si}, \mathrm{Fe}, \mathrm{P}, \mathrm{S}$, As and sum of $\mathrm{Na}_{2} \mathrm{O}$ and $\mathrm{K}_{2} \mathrm{O}$ are lower than $0.25 \%, 0.30 \%, 0.05 \%, 0.03 \%, 0.02 \%, 1.5 \%$ respectively.

Table 2. Chemical composition of the vanadium pentoxide product (wt. \%).

\begin{tabular}{cccccccccc}
\hline $\mathrm{V}_{\mathbf{2}} \mathbf{O}_{\mathbf{5}}$ & $\mathbf{M n}$ & $\mathbf{S}$ & $\mathbf{S i}$ & $\mathbf{F e}$ & $\mathrm{Al}$ & $\mathbf{P}$ & $\mathrm{Ca}$ & $\mathbf{N a}_{2} \mathbf{O}$ & $\mathbf{K}_{\mathbf{2}} \mathbf{O}$ \\
\hline 98.63 & 0.85 & 0.011 & 0.031 & 0.012 & 0.011 & 0.016 & 0.007 & - & 0.011 \\
\hline
\end{tabular}




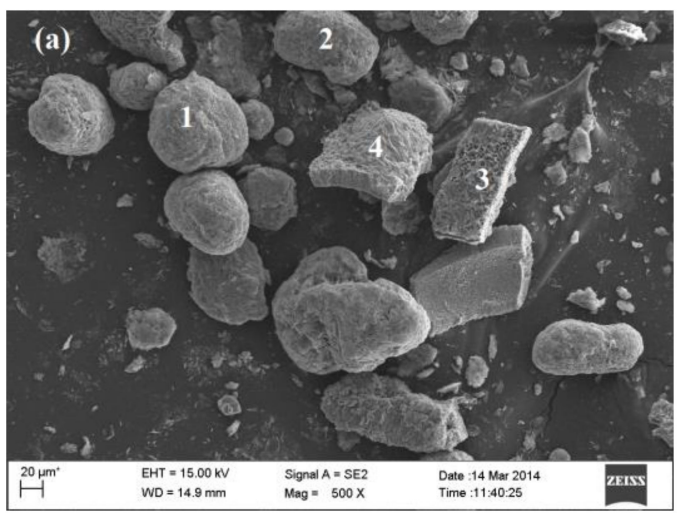

\begin{tabular}{ccccc}
\hline & \multicolumn{4}{c}{ Element, wt. \% } \\
\cline { 2 - 5 } Area & $\mathrm{V}$ & $\mathrm{O}$ & $\mathrm{N}$ & $\mathrm{Mn}$ \\
\hline 1 & 62.18 & 31.28 & 6.54 & - \\
2 & 70.06 & 22.17 & 5.93 & 1.84 \\
3 & 54.31 & 40.06 & 4.89 & 0.73 \\
4 & 50.51 & 43.59 & 5.90 & - \\
\hline
\end{tabular}
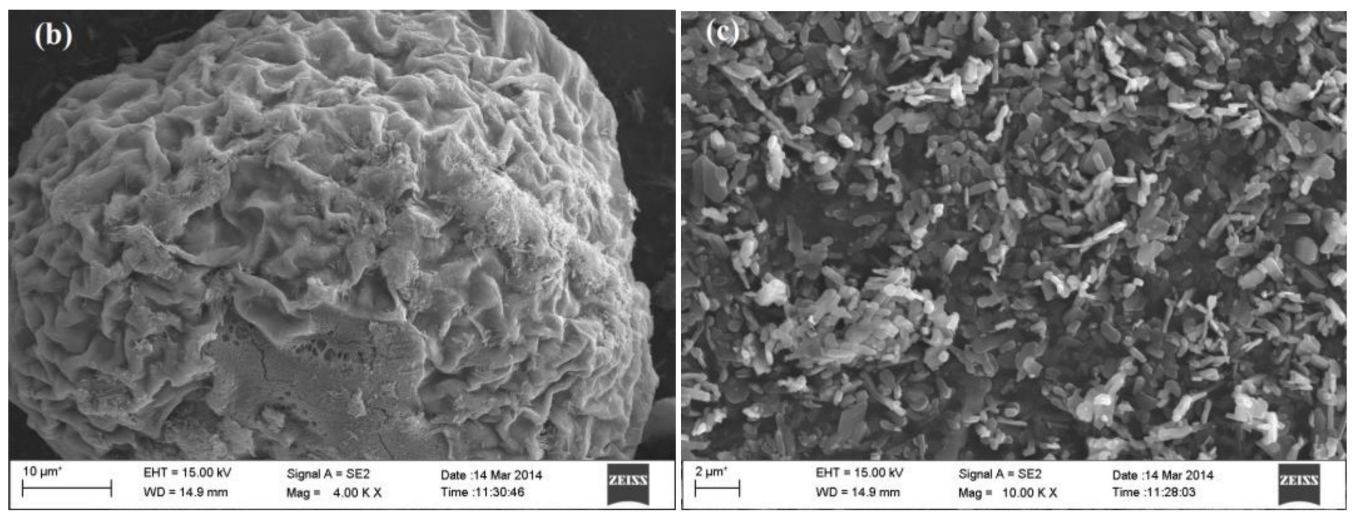

Figure 9. Scanning electron micrographs for ammonium poly-vanadate and vanadium pentoxide powder, (a) ammonium poly-vanadate $\times 500$; (b) ammonium poly-vanadate $\times 4,000$; (c) vanadium pentoxide powder $\times 10,000$.
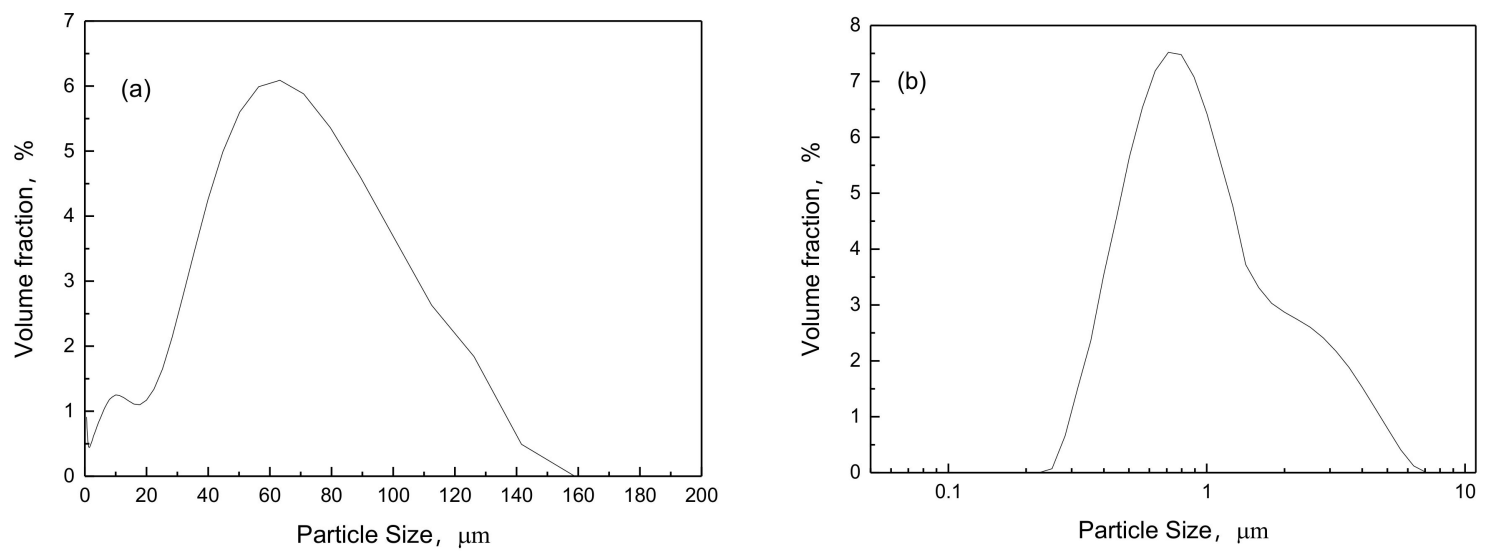

Figure 10. Particle size distribution for ammonium poly-vanadate and vanadium pentoxide (a) ammonium poly-vanadate; (b) vanadium pentoxide.

\subsection{Wastewater and Tailings}

In the purification procedure, $\mathrm{Ca}, \mathrm{Mg}, \mathrm{Al}$ and $\mathrm{Si}$ were removed but $\mathrm{Mn}$ was increased. After vanadium precipitation with ammonium sulfate salt, the main elements contained in the mother liquor were listed in Table 3.

It can be seen that the residual vanadium concentration is $0.69 \mathrm{~g} \cdot \mathrm{L}^{-1}$ and $\mathrm{Mn}$ is $9.82 \mathrm{~g} \cdot \mathrm{L}^{-1}$. If the mother liquor is circulated directly to the leaching step, the quality of vanadium pentoxide product will be lowered as the Mn is gradually enriched. Hence, Mn should be collected before recycle of the mother liquor. In this proposed process, $\mathrm{Mn}$ was recovered by oxalate precipitation method at $\mathrm{pH}$ of 4.0 and temperature of $55^{\circ} \mathrm{C}$. When the oxalate was added at a molar ratio $\left(\mathrm{H}_{2} \mathrm{C}_{2} \mathrm{O}_{4}\right) /(\mathrm{Mn})$ of 1.5 and reaction 
time was beyond $1 \mathrm{~h}$, the recovery of Mn was over $94 \%$. Based on the analysis of XRD and chemical composition, it was found that the precipitated manganese existed as $\mathrm{MnC}_{2} \mathrm{O}_{4}$ with purity of $98.6 \%$.

Table 3. Concentrations of $\mathrm{V}$ and the main impurities contained in mother liquor after vanadium precipitation $\left(\mathrm{g} \cdot \mathrm{L}^{-1}\right)$.

\begin{tabular}{ccccccccc}
\hline $\mathbf{V}$ & $\mathbf{M n}$ & $\mathbf{C a}$ & $\mathbf{M g}$ & $\mathbf{A l}$ & $\mathbf{T i}$ & $\mathbf{C r}$ & $\mathbf{P}$ & $\mathbf{S i}$ \\
\hline 0.69 & 9.82 & 0.016 & 0.061 & 0.006 & 0.003 & 0.010 & 0.055 & 0.70 \\
\hline
\end{tabular}

After the manganese was extracted, the mother liquor was reused to leach the roasted slag. In our study, the wastewater was recycled six times, and relationships between the number of recycle and the concentrations of impurities in the leaching solution were shown in Figure 11. Correspondingly, the effects of number of recycling mother liquor on the quality of vanadium pentoxide were shown in Table 4.
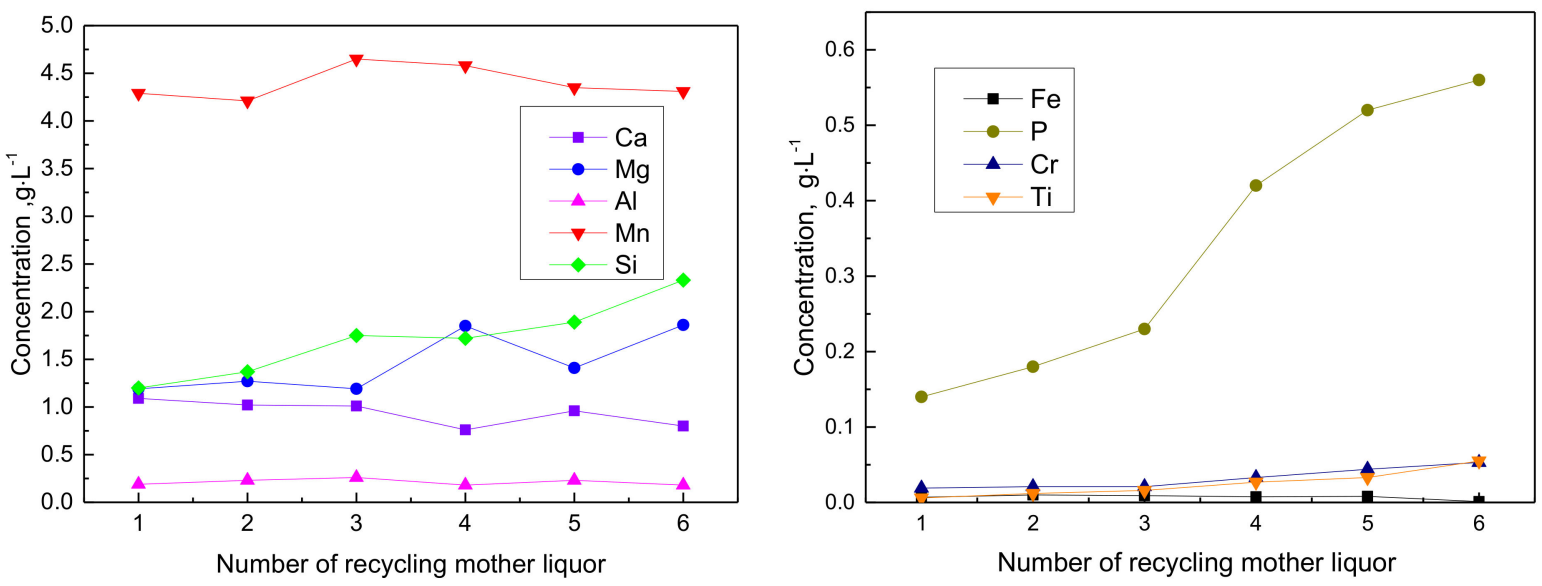

Figure 11. Relationships between concentrations of impurities and the number of recycling mother liquor (a) variation of the concentration of main impurities of $\mathrm{Ca}, \mathrm{Mg}, \mathrm{Al}, \mathrm{Mn}$ and $\mathrm{Si}$ as the recycle increases; (b) variation of the concentration of the minor impurities of $\mathrm{Fe}, \mathrm{P}, \mathrm{Cr}$ and $\mathrm{Ti}$ as the recycle increases.

Table 4. Effect of the number of recycling mother liquor on the quality of final product (wt. \%).

\begin{tabular}{ccccccccccccc}
\hline Number of Recycle & $\mathbf{V}_{\mathbf{2}} \mathbf{O}_{\mathbf{5}}$ & $\mathbf{M n}$ & $\mathbf{S i}$ & $\mathbf{C r}$ & $\mathbf{T i}$ & $\mathbf{F e}$ & $\mathbf{S}$ & $\mathbf{A l}$ & $\mathbf{P}$ & $\mathbf{C a}$ & $\mathbf{M g}$ & $\mathbf{K} \mathbf{O}_{\mathbf{2}}$ \\
\hline 1 & 98.73 & 0.39 & 0.052 & - & - & 0.022 & - & - & 0.014 & 0.020 & - & - \\
2 & 98.63 & 0.73 & 0.023 & - & - & 0.024 & - & 0.010 & 0.021 & 0.034 & - & 0.012 \\
3 & 98.04 & 0.92 & 0.079 & - & 0.035 & 0.019 & 0.007 & 0.011 & 0.022 & 0.011 & 0.005 & 0.020 \\
4 & 97.30 & 1.09 & 0.21 & - & 0.060 & 0.019 & 0.044 & 0.038 & 0.078 & 0.011 & 0.011 & 0.018 \\
5 & 91.65 & 0.53 & 2.41 & 0.164 & 0.114 & 0.024 & 0.132 & 0.035 & 0.308 & 0.064 & 0.040 & 0.031 \\
6 & 88.00 & 0.50 & 4.55 & 0.137 & 0.258 & 0.021 & 0.196 & 0.024 & 0.279 & 0.050 & 0.034 & 0.033 \\
\hline
\end{tabular}

As shown in Figure 10, as the number of recycling mother liquor increases, the concentrations of main impurities, like $\mathrm{Ca}, \mathrm{Mg}$, $\mathrm{Al}$ and $\mathrm{Mn}$, fluctuate slightly while Si increases gradually because only a portion of it is removed in purification operation every time. Meanwhile, the minority impurities such as $\mathrm{Cr}$, Ti and $\mathrm{P}$ are enriched with an increase in circulations of mother liquor. The concentration of Fe is almost constant and lower than $0.010 \mathrm{~g} / \mathrm{L}$ since the solubility of Fe is only related to the $\mathrm{pH}$ of leaching solution system. From Table 4, it was found the quality of vanadium pentoxide still meets the standard of grade 98 when the mother liquor is reused for three times. However, as the number of circulations is increased, the contents of $\mathrm{Si}$ and $\mathrm{P}$ in the product both go up. Meanwhile the minority impurities of Ti and $\mathrm{Cr}$ have little effect on the quality of vanadium pentoxide in the first two times of circulation, but as the mother liquor is circulated further, the increasing content of $\mathrm{Ti}$ and $\mathrm{Cr}$ also bring side effect to the grade of vanadium pentoxide. Hence, in order to realize closed recycle of the wastewater, the mother liquor has to be treated when the impurities is enriched to a certain extent. In this proposed process, 
powder $\mathrm{CaO}$ was added to neutralize the solution and precipitate the enriched impurities like $\mathrm{Si}, \mathrm{P}$, $\mathrm{Cr}$ and $\mathrm{Ti}$. When the $\mathrm{pH}$ was improved to 8.6, the stirring was stopped and then the solution was allowed to stand for $10 \mathrm{~min}$. After analysis, it was found that the residual impurities were satisfactory, the concentration of Si lower than $75 \mathrm{mg} \cdot \mathrm{L}^{-1}$ and $\mathrm{P}, \mathrm{Cr}, \mathrm{Ti}$ all lower than $3 \mathrm{mg} \cdot \mathrm{L}^{-1}$, and this solution could be recycled to leach the roasted slag again.

The main chemical composition and XRD pattern for tailings produced in this process were shown in Table 5 and Figure 12.

Table 5. Chemical composition of tailings after vanadium extraction with calcified roasting-acid leaching (wt. \%).

\begin{tabular}{ccccccccc}
\hline $\mathrm{V}_{\mathbf{2}} \mathrm{O}_{5}$ & $\mathrm{Fe}_{2} \mathrm{O}_{\mathbf{3}}$ & $\mathrm{SiO}_{2}$ & $\mathrm{CaO}$ & $\mathrm{MnO}$ & $\mathrm{TiO}_{2}$ & $\mathrm{Cr}_{\mathbf{2}} \mathrm{O}_{3}$ & $\mathbf{M g O}$ & $\mathbf{A l}_{2} \mathbf{O}_{3}$ \\
\hline 1.20 & 33.24 & 10.97 & 15.91 & 6.45 & 7.08 & 4.70 & 2.33 & 1.54 \\
$\mathrm{P}_{2} \mathrm{O}_{5}$ & $\mathrm{SO}_{3}$ & $\mathrm{Nb}_{2} \mathrm{O}_{5}$ & & & & & & \\
0.49 & 16.05 & 0.047 & & & & & & \\
\hline
\end{tabular}

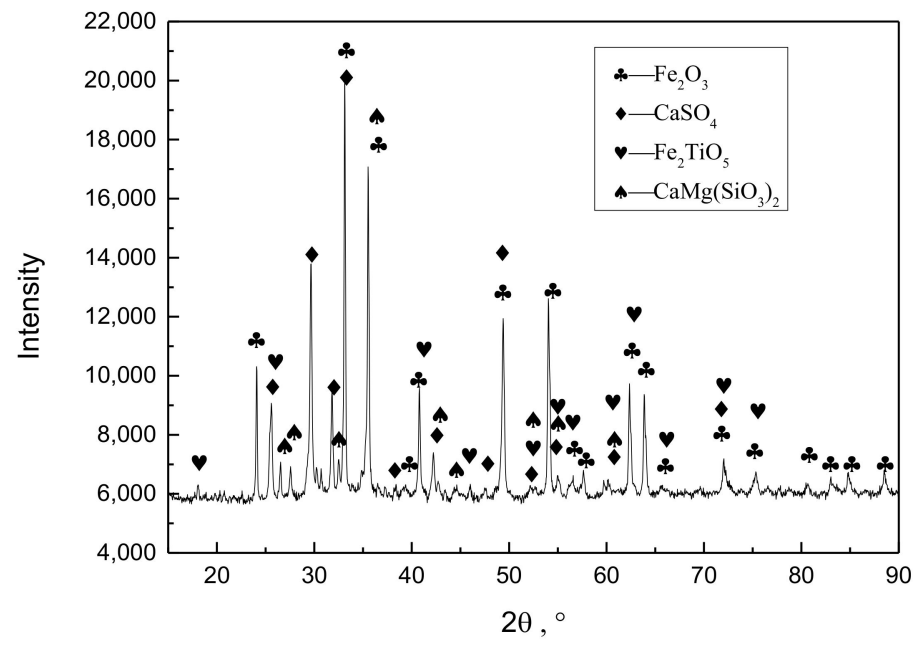

Figure 12. XRD pattern for tailings of vanadium extraction.

After vanadium extraction, the tailings contained $1.20 \% \mathrm{~V}_{2} \mathrm{O}_{5}$, which can also be recycled to roasting step at a certain ratio to lower the residual content of vanadium. As shown in Table 5 it was found that the tailings from this proposed process are rich in calcium and almost free of sodium, which is beneficial to recover other valuable metals like $\mathrm{Fe}, \mathrm{Cr}$, Mn and Ti with the traditional pyrometallurgical process since we know that high contents of sodium will bring serious damage to refractories.

\section{Evaluation of the Proposed Process and Conclusions}

The proposed process for vanadium pentoxide production in this paper mainly includes five operational steps of calcified roasting, dilute acid leaching, chemical precipitation purification, vanadium precipitation with ammonium salt, thermal decomposition and recycle of mother liquor.

Compared with the sodium roasting process widely used in vanadium pentoxide production industry, this process performs best in environmental protection and resource utilization. The traditional vanadium extraction process of sodium roasting followed by water leaching has strict requirements for calcium content in raw vanadium slag. If the content of $\mathrm{CaO}$ is increased by $1 \%$, vanadium leaching rate will decrease by $4.7-9 \%$ due to the formation of water-insoluble vanadate during roasting. On the contrary, powder $\mathrm{CaO}$ is applied as additives in the calcified roasting, and high content of calcium in the raw vanadium slag can decrease the adding amount of additive of $\mathrm{CaO}$. During roasting step, poisonous gases, such as $\mathrm{Cl}_{2}, \mathrm{HCl}, \mathrm{SO}_{2}$ and $\mathrm{SO}_{3}$ are discharged in the sodium 
roasting process, which results from the decomposition of additives of $\mathrm{NaCl}$ and $\mathrm{Na}_{2} \mathrm{SO}_{4}$ at high temperature, while calcified roasting can avoid this problem. Furthermore, calcified roasting can alleviate the phenomenon of burden bonding roasting furnace, which usually happens due to the generation of the low melting-point phase of sodium salts during sodium roasting process.

Since no sodium and potassium salt is introduced in the process, wastewater can be closed-circulating after removing the enriched impurities of $\mathrm{P}, \mathrm{Si}$, $\mathrm{Ti}$ and $\mathrm{Cr}$ with adding powder $\mathrm{CaO}$. In contrast, it is well known that the wastewater from the sodium process contains high concentration of sodium, which is difficult to remove from the aqueous solution, resulting in enrichments of $\mathrm{Na}_{2} \mathrm{SO}_{4}$ which makes the viscosity of mother liquor increased and let the mother liquor not suitable for recycling to leach the roasted slag. In addition, because lots of chromium transfers into the vanadium-bearing solution as $\mathrm{Cr}^{6+}$ during the sodium roasting-water leaching process, the residual chromium in the mother liquor has to be treated with reduction and precipitation. In this proposed process, the valuable metals like $\mathrm{Fe}, \mathrm{Cr}, \mathrm{Ti}, \mathrm{Mn}$ in the tailings after vanadium extraction are more feasible to be comprehensively recovered through conventional pyrometallurgical processes since little $\mathrm{Na}$ is contained. The product of vanadium pentoxide contains little alkaline metals of $\mathrm{Na}$ and $\mathrm{K}$, it will be better to be used in the iron and steel industry.

In the proposed process, a chemical precipitation method was used to purifying the acidic solution. Unlike the conventional method of solvent extraction for purification of acidic vanadium-bearing solution, adding the composite reagent of $\mathrm{Mn}\left(\mathrm{NH}_{4}\right) \mathrm{F}_{3}$ to remove the impurities from the acidic vanadium-bearing solution is easy to operation and convenient to apply in industry, meanwhile, does not bring forth any serious secondary pollution.

In the whole process, from roasting to thermal decomposition, the total vanadium recovery is more than $83 \%(>91 \% \times 95 \% \times 96 \%)$, which is higher than $75 \%$ of that for the conventional sodium roasting process. Manganese resources can be simultaneously recovered as $\mathrm{MnC}_{2} \mathrm{O}_{4}$ with purity of $98.5 \%$ during the proposed process.

In conclusion, the final product of vanadium pentoxide prepared with this proposed process meets the standards of Grade 98 and the total vanadium recovery is higher than $83 \%$, which is a relatively satisfactory vanadium resource utilization rate. In addition, during the whole process, little poisonous gas is discharged, wastewater almost realizes closed recycle, and the tailing after vanadium extraction is rich in $\mathrm{Ca}$ and favor to be treated with pyrometallurgy to recover other valuable metal resources.

Author Contributions: Conceptualization, J.Z.; Methodology, J.Z. and W.Z.; Software, J.Z. and W.Z., Validation, J.Z.; Formal Analysis, J.Z., W.Z. and Z.X.; Investigation, J.Z.; Resources, J.Z.; Data curation, J.Z., W.Z. and Z.X.; Writing-Original Draft Preparation, J.Z.; Writing-Review \& Editing, W.Z. and Z.X.; Visualization, W.Z.; Supervision, Z.X.; Project Administration, Z.X.; Funding Acquisition, J.Z.

Funding: This project was financially supported by the National Natural Science Foundation of China (No. 51804230, 51804228) and the Scientific Research Project of Education Department of Hubei Province (No. Q20181108).

Acknowledgments: We gratefully acknowledge the Sichuan Weiyuan Iron \& Steel Co., Ltd. for providing samples of vanadium slag and thank Aihua Liu for her contributions during collecting the data of particle size.

Conflicts of Interest: The authors declare no conflict of interest. The funders had no role in the design of the study; in the collection, analyses, or interpretation of data; in the writing of the manuscript, and in the decision to publish the results.

\section{References}

1. Moskalyk, R.R.; Alfantazi, A.M. Processing of vanadium: A review. Miner. Eng. 2003, 16, 793-805. [CrossRef]

2. Xu, J.Q.; Chen, G.R.; Guo, F.; Xie, J.Q. Development of wide-temperature vanadium-based catalysts for selective catalytic reducing of NOx with ammonia: Review. Chem. Eng. J. 2018, 353, 507-518. [CrossRef]

3. Edgar, D.C.; Lino, H.; Carlos, C.; Valentina, V.C.; Lisseetle, J.; Vito, L.; Giuseppe, L. Vanadium: History, chemistry, interactions with $\alpha$-amino acids and potential therapeutic applications. Coordin. Chem. Rev. 2018, $372,117-140$. 
4. Li, M.; Liu, B.; Zheng, S.L.; Wang, S.M.; Du, H.; Dreisinger, D.B.; Zhang, Y. A cleaner vanadium extraction method featuring non-salt roasting and ammonium bicarbonate leaching. J. Clean. Prod. 2017, 149, $206-217$. [CrossRef]

5. Wu, K.H.; Wang, Y.R.; Wang, X.R.; Wang, S.N.; Liu, B.; Zhang, Y.; Du, H. Co-extraction of vanadium and chromium from chromium containing vanadium slag by low-pressure liquid phase oxidation method. J. Clean. Prod. 2018, 203, 873-884. [CrossRef]

6. Liu, B.; Du, H.; Wang, S.N. A novel method to extract vanadium and chromium from vanadium slag using molten $\mathrm{NaOH}-\mathrm{NaNO}_{3}$ binary system. AIChE J. 2013, 59, 541-552. [CrossRef]

7. Liu, F.; Ning, P.G.; Cao, H.B.; Zhang, Y. Measurement and modeling for vanadium extraction from the $\left(\mathrm{NaVO}_{3}+\mathrm{H}_{2} \mathrm{SO} 4+\mathrm{H}_{2} \mathrm{O}\right)$ system by primary amine N1923. J. Chem. Thermodyn. 2015, 80, 13-21. [CrossRef]

8. Wang, Z.H.; Zheng, S.L.; Wang, S.N.; Qin, Y.L.; Du, H.; Zhang, Y. Electrochemical decomposition of vanadium slag in concentrated $\mathrm{NaOH}$ solution. Hydrometallurgy 2015, 151, 51-55. [CrossRef]

9. Zhang, G.Q.; Zhang, T.A.; Lv, G.Z.; Zhang, Y.; Liu, Y.; Xie, G. Extraction of vanadium from LD converter slag by pressure leaching process with titanium white waste acid. Rare Metal Mat. Eng. 2015, 44, 1894-1898.

10. Liu, Z.H.; Li, Y.; Chen, M.L.; Nueraihemaiti, A.; Du, J.; Fan, X.; Tao, C.Y. Enhanced leaching of vanadium slag in acidic solution by eletro-oxidation. Hydrometallurgy 2016, 159, 1-5. [CrossRef]

11. Mirazimi, S.M.J.; Rashchi, F.; Saba, M. A new approach for direct leaching of vanadium from LD converter slag. Chem. Eng. Res. Des. 2015, 94, 131-140. [CrossRef]

12. Zhang, G.Q.; Luo, D.M.; Deng, C.H.; Lv, L.; Liang, B.; Li, C. Simultaneous extraction of vanadium and titanium from vanadium slag using ammonium sulfate roasting-leaching process. J. Alloy Compd. 2018, 742, 504-511. [CrossRef]

13. Zhang, J.H.; Zhang, W.; Xue, Z.L. Oxidation kinetics of vanadium slag roasting in the presence of calcium oxide. Min. Proc. Ext. Met. Rev. 2017, 38, 265-273. [CrossRef]

14. Xiang, J.Y.; Huang, Q.Y.; Lv, X.W.; Bai, C.G. Extraction of vanadium from converter slag by two-step sulfuric acid leaching process. J. Clean. Prod. 2018, 170, 1089-1101. [CrossRef]

15. Zhang, J.H.; Zhang, W.; Zhang, L.; Gu, S.Q. A critical review of technology for selective recovery of vanadium from leaching solution in $\mathrm{V}_{2} \mathrm{O}_{5}$ production. Solvent Extr. Ion Exc. 2014, 32, 221-248. [CrossRef]

16. Sun, Z.H. Analysis on new vanadium technologies and prospects of vanadium industry. Iron Steel Vanadium Titan. 2012, 33, 1-7. (In Chinese)

17. Chen, H.S. Study on the vanadium extraction from vanadium slag with lime roasting process. Iron Steel Vanadium Titan. 1992, 13, 1-9. (In Chinese)

18. Cao, P. Research on vanadium slag roasted with calcium salt. Iron Steel Vanadium Titan. 2012, 33, 30-34. (In Chinese)

19. Yin, D.F.; Peng, Y.; Sun, Z.H.; He, W.Y. Influencing factors of calcified roasting and thermal analysis to the process of vanadium slag produced from Pangang. Metal Mine 2012, 4, 91-94. (In Chinese)

20. Fu, Z.B. Experimental research on vanadium extraction by calcified roasting and acid leaching. Iron Steel Vanadium Titan. 2014, 35, 1-6. (In Chinese)

21. Wang, M.H.; Liu, Z.H.; Zhao, H.; Liu, Y.; Lou, T.P.; Sun, Z.H.; Tang, H.J.; Jing, H. Measurement of calcification of vanadium slag by XRD semi-quantitative method. Iron Steel Vanadium Titan. 2018, 39, 6-12. (In Chinese) [CrossRef]

22. Zhang, J.H.; Zhang, W.; Zhang, L.; Gu, S.Q. Mechanism of vanadium slag roasting with calcium oxide. Int. J. Mine. Process. 2015, 138, 20-29. [CrossRef]

23. Zhang, J.H.; Zhang, W.; Zhang, L.; Gu, S.Q. Effect of acid leaching on the vanadium leaching rate in process of vanadium extraction using calcium roasting. J. Northeast. Univ. Nat. Sci. 2014, 35, 1574-1578. (In Chinese)

24. Zhang, J.H.; Yan, Z.F.; Zhang, L. Influence factors and kinetics of vanadium precipitation for the vanadium solution from calcified vanadium extraction. J. Process Eng. 2018, 18, 111-117. (In Chinese)

(C) 2018 by the authors. Licensee MDPI, Basel, Switzerland. This article is an open access article distributed under the terms and conditions of the Creative Commons Attribution (CC BY) license (http:/ / creativecommons.org/licenses/by/4.0/). 